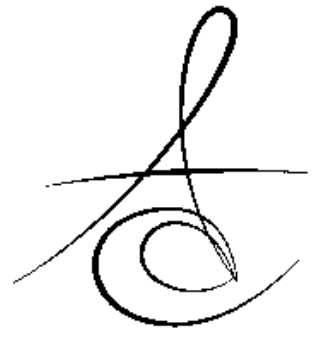

\title{
FARKLI DEZENFEKTAN AJANLARIN SİLİKON ESASLI ÖLÇÜ MADDELERİNİN YÜZEY PÜRÜZLÜLÜĞÜNE ETKİSİ
}

\section{EFFECT OF DIFFERENT DISINFECTANT AGENTS ON SURFACE ROUGHNESS OF SILICONE- BASED IMPRESSION MATERIALS}

\author{
Arş.Gör.Dt. Alper ÖZDOĞAN* \\ Arş Gör.Dt. Esra İNCESU* \\ Arş.Gör.Dt. Özlem ÖZBAYRAM*
}

\author{
Prof.Dr. Funda BAYINDIR* \\ Prof.Dr. Zeynep YEŞİL DUYMUŞ ${ }^{* *}$ \\ Arş.Gör.Dr. Yasemin KAYA***
}

Makale Kodu/Article code: 2523

Makale Gönderilme tarihi: 21.12.2015

Kabul Tarihi: 05.02.2016

\section{öz}

Amaç: $\mathrm{Bu}$ çalışmanın amacı farklı dezenfektan ajanların silikon esaslı ölçü maddelerinin yüzey pürüzlülüğüne etkisinin incelenmesidir.

Gereç ve Yöntem: Çalışma kapsamında iki farklı silikon esaslı ölçü maddesinden oluşan toplam 80 adet örnek kullanıldı. Örnekler dezenfeksiyon işlemine göre 4'er gruba ayrıldı ve dezenfektan ajanlarda 1 gün süre ile bekletildi. 1 günü takiben profilometre cihazı ile yüzey pürüzlülük ölçümü yapıldı. Verilerin istatistiksel analizi iki yönlü varyans analizi testi (ANOVA) kullanılarak yapıldı.

Bulgular: İki yönlü varyans analizi verilerine göre, dezenfektan ajanların silikon esaslı ölçü maddelerinin yüzey pürüzlülüğünü istatistiksel olarak etkilemediği bulunmuştur ( $p>0,05)$.

Sonuç: Elde edilen veriler ışığında, dezenfeksiyon işlemi ölçü maddelerinin yüzeyinde herhangi bir değişiklik oluşturmamakta ve ölçünün netliğini etkilememektedir.

Anahtar Kelimeler: Dezenfeksiyon, ölçü maddesi, yüzey pürüzlülüğü.

\section{ABSTRACT}

Aim: The aim of this study was to evaluate the effect of different disinfectant agents on surface roughness of silicone-based impression materials.

Materials and Methods: Totally 80 specimens were used including of two different silicone-based impression materials in this study. Specimens were divided into four groups according to disinfection and stored in disinfectant agents for a day. After a day, the surface roughness was performed with profilometer. The statistically analysis of obtained data were performed with use two-way analysis of variance test (ANOVA).

Results: The result of two-way analysis of variance test showed that there were no statically significant differences surface roughness of silicone-based impression materials $(p>0,05)$.

Conclusion: The obtained data presented that the disinfection was not changing the surface roughness and not effect details of silicone-based impression materials.

Key Words: Disinfection, impression material, surface roughness

\section{GİRIŞ}

Sabit diş hekimliği kliniğinde protetik restorasyonların yapım aşamalarından birisi olan ölçü alma işlemi önemli bir basamaktır. Sabit protetik restorasyonların ölçü işlemlerinde; detayları çok iyi kaydedebilmesi, manipülasyon kolaylığı, aynı ölçüden iki model elde edilebilmesi ve boyutsal yönden stabil olması nedeniyle silikon esaslı ölçü maddeleri rutin olarak kullanılmaktadır. ${ }^{1}$ Silikon esaslı ölçü maddeleri kondanse ve ilave tipli olmak üzere iki ana gruba ayrılır. Kondanse tipli ölçü maddesinin ana maddesi polivinil siloksandır, tatsız ve kokusuz olmalarından dolayı tercih edilmektedir ancak yan ürün olarak etil alkol açığa çıkarıp ölçü yüzeyinde bozulmaya yol açarlar ve ölçü alındıktan sonra hemen dökülmesi

${ }^{*}$ Atatürk Üniversitesi Diş Hekimliği Fakültesi Protetik Diş Tedavisi AD

${ }^{* *}$ Recep Tayyip Erdoğan Üniversitesi Diş Hekimliği Fakültesi, Protetik Diş Tedavisi AD

${ }^{* * *}$ Atatürk Üniversitesi Kazım Karabekir Eğitim Fakültesi, Eğitim Bilimleri Bölümü 
gerekir. $^{2}$ Kondensasyon silikonların modifikasyonu olarak ortaya çıkan ilave reaksiyonlu silikonlar ise (polivinil siloksan) 1970'li yıllarda kullanılmaya başlanmıştır. Her iki tip ölçü maddesi de kimyasal yapılarından dolayı hidrofobik özellik gösterir, vizkozitelerine göre ise hafif, orta, ağır ve çok ağır olmak üzere dört gruba ayrılırlar. ${ }^{3}$ Ancak günümüzde içerdikleri ilave ekstrinsik aktif maddeler sayesinde hidrofilik olarak etiketlenmektedirler. ${ }^{4,5}$

Patojen mikroorganizmaların çeşitli bulaşma yolları ile bir canlıdan diğerine geçmelerine ve o canlıda meydana getirdikleri enfeksiyona çapraz enfeksiyon denilmektedir. $^{6} \quad$ Gerek ölçü alma işlemi gerekse ölçüden model elde edilmesi sırasında hasta, diş hekimi, yardımcı personel ve diş teknisyeni arasında kan ve tükürük yoluyla bulaşabilecek mikroorganizmaların yaratabileceği bir çapraz enfeksiyon riski mevcuttur. ${ }^{7}$

Protetik işlemler sırasında bu çapraz enfeksiyon riskinin en üst düzeye ulaştığı safha ölçü safhasıdır ve sterilizasyon işleminin uygulanamadığı bu safhada kimyasal dezenfektanlar devreye girmektedir. ${ }^{8}$ Diş protez klinik ve laboratuvarları çapraz bulaşma konusunda en önemli alan olma özelliğini taşımakta ve hasta-hekim-laboratuvar üçgeni içinde bir koruyucu bariyer tekniği geliştirilerek, hastanın ağzından çıkarıldıktan sonra bütün ölçüler ve protezler dezenfekte edildikten sonra laboratuvara gönderilmelidir. ${ }^{9}$

Amerikan Diş Hekimleri Birliği (ADA) dezenfeksiyon için ölçü maddelerinin yıkanıp kan ve tükürüğün tamamen uzaklaştırılmasını takiben hipoklorit, iodofor, gluteraldehit veya fenol bileşiklerinde 10-15 dakika süreyle bekletilmesini önermiştir. ${ }^{10}{ }^{11}$ Ancak ölçülerde kullanılmakta olan dezenfeksiyon yöntemlerinin ölçünün stabilitesi ve yüzey netliği gibi özelliklerini olumsuz yönde etkilediği belirtilmektedir. ${ }^{12,13}$

$\mathrm{Bu}$ çalışmamızda farklı dezenfektan ajanların silikon esaslı ölçü maddelerinin yüzey pürüzlülüğü üzerine etkisinin incelenmesi amaçlanmıştır. Çalışmamızın hipotezi ise, dezenfektan ajanların ölçü maddelerinin yüzey pürüzlülüğünü etkileyeceği yönündedir.

\section{GEREÇ VE YÖNTEM}

Çalışma kapsamında, biri kondanse C tipi (exaplast, DETAX Dental GmbH, Almanya) diğeri ilave A tipi (Elite HD Fast Set, Zhermack, İtalya) olmak üzere iki farklı silikon esaslı ölçü maddesi kullanıldı. Her iki ölçü maddesinden $15 \mathrm{~mm}$ çap ve $2 \mathrm{~mm}$ yüksekliğe sahip disk şeklinde 40'ar adet olmak üzere toplam 80 adet örnek hazırlandı. Örnekleri hazırlamak için aynı çap ve boyuta sahip aynı anda 6 adet örneğin hazırlanabildiği metal bir kalıp kullanıldı. C tipi silikon ölçü maddesinin pasta şeklindeki katalizörü ve tüp şeklindeki aktivatörü karıştırılıp rulo haline getirildi.

Daha sonra metal kalıptaki boşluklar içerisine yerleştirildi, kalıbın ön ve arka kısmına siman camı konulup baskı uygulanarak örneklerin içinde boşluk kalmaması ve düzgün yüzeylere sahip olması sağlandı. Örnek kenarlarındaki fazlalıklar keskin uçlu bir bisturi yardımıyla dikkatlice uzaklaştıııldı. Aynı işlem A tipi silikonlar için de pasta şeklinde olan katalizör ve aktivatör homojen bir şekilde karıştırılarak uygulandı (Resim 1). Daha sonra hazırlanan örnekler her bir grupta 10 'ar adet olacak şekilde rastgele dört gruba ayrıldı $(n=10)$. Birer grup kontrol grubu olarak kullanıldı ve dezenfeksiyon işlemi uygulanmadı. Diğer gruplar ise 3 farklı dezenfektan ajan (Actoanid, Mikrozid, Sodyum hipoklorit) kullanılarak kapalı kaplar içerisinde 1 gün boyunca bekletildi. Dezenfektan ajanların üretici firmaları ve içerikleri Tablo 1'de gösterilmiştir. 1 gün sonra örnekler akar su altında iyice yıkanıp kurutuldu.

Yüzey pürüzlülük ölçümleri profilometre cihazı (Surtronic 25; Taylor Hobson, Leicester, U.K.) yardımıyla yapıldı ve kaydedildi. Verilerin istatistiksel analizi iki yönlü varyans analizi testi (ANOVA) kullanılarak yapıldı.

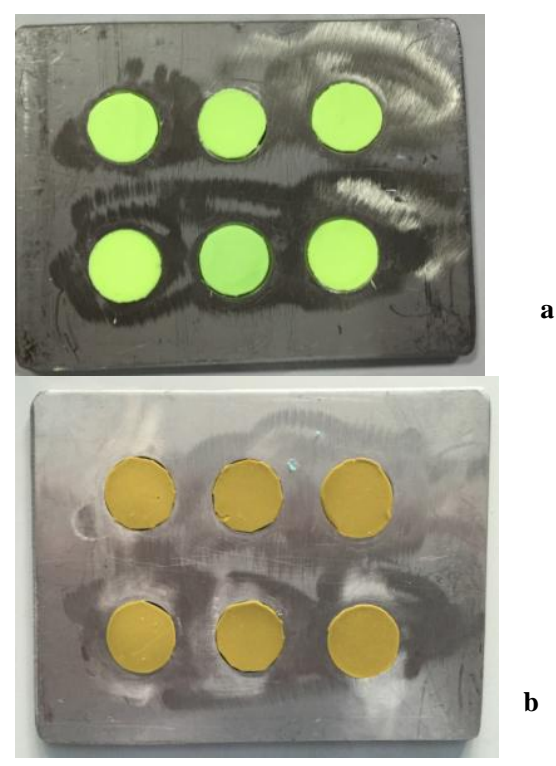

Resim 1. Metal kalıp içerisinde hazırlanan kondanse (a) ve ilave (b) tip silikon örnekler 
Tablo 1. Dezenfektan maddeler

\begin{tabular}{|l|l|l|}
\hline Dezenfektan & $\begin{array}{l}\text { Üretici } \\
\text { Firma }\end{array}$ & İçerik \\
\hline Actoanid Spray & $\begin{array}{l}\text { Acto } \\
\text { GmbH, } \\
\text { Almanya }\end{array}$ & $\begin{array}{l}100 \mathrm{~g} \text { içeriği; 0,23 g } \\
\text { Polimetil biguanid } \\
\text { hidroklorid, 0,28 g } \\
\text { Kuarterner amonyum } \\
\text { bileşikleri }\end{array}$ \\
\hline $\begin{array}{l}\text { Mikrozid AF } \\
\text { Liquid }\end{array}$ & $\begin{array}{l}\text { Schülke\& } \\
\text { Mayr } \\
\text { GmbH, } \\
\text { Almanya }\end{array}$ & $\begin{array}{l}\text { propan-1-ol, \%0,05 } \\
\text { surfaktan, \%0,02 } \\
\text { parfum, \%39,93 su }\end{array}$ \\
\hline $\begin{array}{l}\text { Sodyum } \\
\text { Hipoklorit (1:10 } \\
\text { sulandırılmış) }\end{array}$ & $\begin{array}{l}\text { Cerkamed } \\
\text { Polonya }\end{array}$ & \begin{tabular}{l} 
Poll \\
\hline
\end{tabular}
\end{tabular}

\section{BULGULAR}

İki yönlü varyans analizi (ANOVA) sonuçlarına göre farklı dezenfektan ajanların kondanse ve ilave tipli silikonların yüzey pürüzlülüğünü istatistiksel olarak etkilemediği görülmüştür ( $p>0,05)$ (Tablo 2).

Sonuçlar en düşük yüzey pürüzlülüğü değerinin $(1,70 \pm 0,47 \mu \mathrm{m})$ ile dezenfeksiyon işlemi yapılmamış (kontrol grubu) ilave tipli silikon ölçü maddesinde, en yüksek yüzey pürüzlülüğü değerinin ise $(2,62 \pm 1,24$ $\mu \mathrm{m}$ ) ile sodyum hipoklorit uygulanmış kondanse silikon ölçü maddesinde olduğunu göstermiştir (Tablo 3).

Tablo 2. İki yönlü varyans analizi sonuçları

\begin{tabular}{|l|c|c|c|c|}
\hline Varyasyon Kaynakları & $\begin{array}{c}\text { Serbestlik } \\
\text { Derecesi }\end{array}$ & $\begin{array}{c}\text { Kareler } \\
\text { Ortalaması }\end{array}$ & $\mathrm{F}$ & $\mathrm{p}$ \\
\hline Silikon & 1 & 1.741 & 3.066 & .084 \\
\hline Dezenfektan & 3 & .851 & 1.499 & .222 \\
\hline Silikon*dezenfektan & 3 & .384 & .676 & .570 \\
\hline Hata & 72 & .568 & & \\
\hline Toplam & 80 & & & \\
\hline
\end{tabular}

Tablo 3. Ortalama yüzey pürüzlülük değerleri

\begin{tabular}{|l|l|c|c|c|}
\hline $\begin{array}{l}\text { Siliko } \\
\mathrm{n}\end{array}$ & Dezenfektan & $\begin{array}{c}\text { Ortala } \\
\text { ma }\end{array}$ & $\begin{array}{c}\text { Standar } \\
\text { t Sapma }\end{array}$ & $\mathrm{N}$ \\
\hline \multirow{4}{*}{ İlave } & Actoanid & 2,33 &, 71 & 10 \\
\cline { 2 - 5 } & Sodyum hipoklorit & 2,17 &, 37 & 10 \\
\cline { 2 - 5 } & Kontrol & 1,70 &, 47 & 10 \\
\cline { 2 - 5 } & Mikrozid & 2,01 &, 72 & 10 \\
\cline { 2 - 5 } & Toplam & 2,05 &, 61 & 40 \\
\hline \multirow{4}{*}{$\begin{array}{l}\text { Kond } \\
\text { anse }\end{array}$} & Actoanid & 2,21 &, 79 & 10 \\
\cline { 2 - 5 } & Sodyum hipoklorit & 2,62 & 1,24 & 10 \\
\cline { 2 - 5 } & Kontrol & 2,12 &, 57 & 10 \\
\cline { 2 - 5 } & Mikrozid & 2,44 &, 79 & 10 \\
\cline { 2 - 5 } am & Toplam & 2,35 &, 87 & 40 \\
\cline { 2 - 5 } & Actoanid & 2,27 &, 73 & 20 \\
\cline { 2 - 5 } & Sodyum hipoklorit & 2,39 &, 92 & 20 \\
\cline { 2 - 5 } & Kontrol & 1,91 &, 55 & 20 \\
\cline { 2 - 5 } & Mikrozid & 2,22 &, 77 & 20 \\
\cline { 2 - 5 } & Toplam & 2,20 &, 76 & 80 \\
\hline
\end{tabular}

\section{TARTIŞMA}

Farklı dezenfektan ajanlar silikon esaslı ölçü maddelerinin yüzey pürüzlülüğünü istatistiksel olarak etkilemediğinden dolayı başlangıçta kurmuş olduğumuz hipotez reddedilmiştir.

Bir protetik restorasyonun yapımı, hasta, hekim, yardımcı personel, teknisyen gibi kişileri; ölçü alımı, model elde edilmesi, laboratuvar aşamaları gibi faktörleri içerdiğinden dolayı çok yönlü yaklaşılması gereken bir süreçtir. Bu elemanlar arasında doğrudan veya dolaylı bir bağlantı olduğu için dezenfeksiyon ve sterilizasyon konusunda yapılacak bir hata tüm sistemi ilgilendirecektir.

Zincirin en başındaki aşamalarından birisi olan ölçü alma işleminde dikkatli davranılmazsa hastalar, diş hekimi, yardımcı personel ve teknisyen arasında çapraz enfeksiyona neden olunabilir. ${ }^{14,15}$

Ölçülerin laboratuvara gelmesinden sonra ölçülerin veya ölçülerden elde edilen modellerin dezenfeksiyonu şeklinde iki yol önerilmektedir. ${ }^{16-18}$ Ancak çapraz enfeksiyonu önlemek ve optimum dezenfeksiyonu sağlamak için ölçülerin alındıktan sonra laboratuvara iletilmeden önce dezenfekte edilmesi gerekmektedir.

Sabit protezlerin yapımı sırasında hastalar tarafından kolay kabul edilmesi, deforme olmaması, net ve detaylı ölçü vermesi, boyutsal yönden stabil olması ${ }^{1}$ 19, 20 gibi üstün özelliklerinden dolayı silikon esaslı ölçü maddeleri sıklıkla kullanılmaktadır. Bu nedenlere bağlı olarak çalışmamızda da kondanse ve ilave tipli olmak üzere iki farklı silikon esaslı ölçü maddesi tercih edilmiştir.

Ölçü maddelerinin dezenfeksiyonu için kullanılacak dezenfektan ajanın tipi ve bu ajanın optimal performansı için; ölçü maddesinin tipine ve zamana, sulandırma ve ısıya bağlı olarak değişiklik gösterdiği ADA tarafından belirtilmiştir. ${ }^{21}$ Çalışmamızda klinikte yüzey dezenfeksiyonu için kullandığımız dezenfektan ajanları tercih edildi ve 1 günlük süre sonundaki etkileri değerlendirildi.

Dezenfektan maddelerin ölçü maddelerinin boyutsal değişimi ve yüzey netliklerine etkisini inceleyen pek çok çalışma yapılmıştır. ${ }^{11,}{ }^{22-24}$ Rowe ve Forrest ${ }^{17} 1978$ yılında, aljinat, tiokol elastomer, silikon elastomer ve polieter ölçü maddelerini klorheksidin çözeltisi içinde bekleterek elde ettikleri alçı modellerin pürüzlülük, porozite ve diğer yüzey defektlerine 
bakarak su içinde bekletilenlerle kıyaslamışlar ve $\% 0,5^{\prime}$ lik klorheksidinin \%70'lik alkol içindeki çözeltisinin dezenfeksiyon için uygun olduğunu bildirmişlerdir.

Al Kheraif ${ }^{25}$ polivinil siloksan ölçü maddelerine uyguladığı kimyasal dezenfeksiyon ve otoklav sterilizasyonunun yüzey pürüzlülüğünü istatistiksel olarak artırmadığını, mikrodalga sterilizasyonunun ise pürüzlülüğü artırdığını bildirmiştir. Yapılan çalışma sonucunda elde edilen değerler dezenfektan ajanların ilave ve kondanse silikonların yüzey pürüzlülüğünü istatistiksel olarak etkilemediğini göstermiştir ve bu durum Al Kheraif'i ${ }^{25}$ desteklemektedir. Amin ve ark. ${ }^{26}$ ölçü maddelerine uyguladıkları dezenfeksiyon işlemini takiben en iyi yüzey netliğinin ilave tipli silikonlarda sonra da kondanse silikonlarda olduğunu, aljinat ve çinko oksit öjenol ölçü maddelerinin ise daha düşük bir yüzey netliğine sahip olduğunu bildirmişlerdir. Khaledi ve ark. ${ }^{27}$ doku düzenleyici bir maddeye uyguladıkları $\% 5.25$ sodyum hipoklorit ve $\% 2$ gluteraldehit'in yüzey pürüzlülüğünü etkilemediğini bildirmişlerdir.

Literatürde dezenfektan maddelerin ölçü maddelerinin boyutsal değişimlerine etkisi ile ilgili çok sayıda çalışma ${ }^{18,28-35}$ bulunmasına karşın, pürüzlülük ile ilgili fazla sayıda çalışmaya rastlanmamıştır. Dezenfeksiyon işleminin ölçü maddelerinin yüzey pürüzlülüğü ve netliği ile ilgili daha fazla çalışma yapılması gerektiğini düşünmekteyiz.

\section{SONUÇ}

Bu çalışmanın sonuçlarına göre, dezenfeksiyon amacıyla kullanılan farklı maddelerin silikon esaslı ölçü maddelerinin yüzey pürüzlülüğünü etkilemediği, kondanse ve ilave tipli silikonların pürüzlülük değerleri arasında istatistiksel olarak farklılık olmadığı tespit edilmiştir. Dezenfeksiyon işlemi ölçü maddelerinin yüzeyinde bir bozulma veya değişiklik oluşturmadığı için ölçü maddesinin netliğini etkilememektedir.

\section{KAYNAKLAR}

1. Phillips RW. Materials for the Practicing Dentist, The C.V. Mosby Co., Saint Louis. 1969.

2. Çağlar İ, Yeşil Duymuş Z, Ateş SM. Diş hekimliğinde kullanılan ölçü sistemlerinde güncel yaklaşımlar: Dijital ölçü, Atatürk Üniv Diş Hek Fak Derg 2015: 25; 135-40.
3. Hamalian TA, Nasr E, Chidiac JJ. Impression materials in fixed prosthodontics: influence of choice on clinical procedure. J Prosthodont 2011; 20: $153-60$.

4. Kess RS, Combe EC, Sparks BS. Effect of surface treatments on the wettability of vinyl polysiloxane impression materials. J Prosthet Dent 2000; 84: 98-102.

5. Lu H, Nguyen B, Powers JM. Mechanical properties of 3 hydrophilic addition silicone and polyether elastomeric impression materials. J Prosthet Dent 2004; 92: 151-4.

6. Block SS. Disinfection, sterilization and preservation. Lea and Febiger Co London. 1991.

7. Ünalan F, Akşit SK, Nakipoğlu R, Duran Ö, Gürler B. Aljinat ve çinko oksit öjenal ölçü maddelerinin dezenfeksiyonunda çeşitli dezenfektanların etkinliği, ANKEM Derg 11 (No.1). 1997; 30-35.

8. Guidelines for Infection Control in the Dental Office and the Commercial Dental Laboratory. J Am Dent Assoc 1985; 110:969-72.

9. Mısırlıgil A, Yazıcıoğlu $H$, Gürbüz A. Çeşitli dezenfektan ajanların protez ölçü maddeleri üzerindeki antibakterial etkilerinin araştırılması, Atatürk Üniv Diş Hek Fak Derg 1996;6: 26-30.

10. Palenik CJ, Burke FJ, Miller $\mathrm{CH}$. Strategies for dental clinic infection control. Dent Update 2000; 27: 7-10, 12, 14-5.

11. Abdelaziz KM, Hassan AM, Hodges JS. Reproducibility of sterilized rubber impressions. Braz Dent J 2004; 15: 209-13.

12. Akçaboy C, Suca S. Ölçü maddeleri ve klinik uygulamaları. I. Baskı, G.Ü. İletişim Fak., Matbaası, Ankara. 1993.

13. Owen CP, Goolam R. Disinfection of impression materials to prevent viral cross contamination: a review and a protocol. Int J Prosthodont 1993; 6: 480-94.

14. Şahmalı S, Saygılı G, Belek S. Silikon ve irreversibl hidrokolloid ölçü materyallerine çeşitli dezenfektan maddelerin etkisi. Mikrobiyoloji bülteni 1991;25: 360-6.

15. Leung RL, Schonfeld SE. Gypsum casts as a potential source of microbial cross-contamination. J Prosthe Dent 1983; 49: 210-1.

16. Council on Dental Materials and Devices : Revised American Dental Association specification No 19 for non - aqueous elastomeric dental impression 
materials. J Am Dent Assoc 1977; 94 : 73-41.

17. Rowe AH, Forrest JO. Dental impressions. The probability of contamination and a method of disinfection. Br Dent J. 1978; 145: 184-6.

18. Sarma AC, Neiman R. A study on the effect of disinfectant chemicals on physical properties of die stone. Quintessence Int 1990; 21: 53-9.

19. Phillips RW. Skinner's Science of Dental Materials, Seventh Ed., W.B. Saunders Co., Philadelphia. 1973.

20. Roberts DH. Fixed Bridge Prostheses, A. John Wright and Sons Ltd., London. 1973.

21. ADA, Guide to Dental Materials and Devices. 6 th. Ed., Chicago. 1972-1973.

22. Silva SM, Salvador MC. Effect of the disinfection technique on the linear dimensional stability of dental impression materials. J Appl Oral Sci 2004; 12: 244-9.

23. Yilmaz H, Aydin C, Gul B, Yilmaz C, Semiz M. Effect of disinfection on the dimensional stability of polyether impression materials. J Prosthodont 2007; 16: 473-9.

24. Boden J, Likeman P, Clark R. Some effects of disinfecting solutions on the properties of alginate impression material and dental stone. Eur J Prosthodont Restor Dent 2001; 9: 131-5.

25. Al Kheraif AA. Surface roughness of polyvinyl siloxane impression materials following chemical disinfection, autoclave and microwave sterilization. J Contemp Dent Pract 2013; 14: 483-7.

26. Amin WM, Al-Ali MH, Al Tarawneh SK, Taha ST, Saleh MW, Ereifij N. The effects of disinfectants on dimensional accuracy and surface quality of impression materials and gypsum casts. J Clin Med Res 2009; 1: 81-9.

27. Khaledi A, Borhanihaghighi Z, Vojdani M. The effect of disinfectant agents on dimensional stability and surface roughness of a tissue conditioner material. Indian J Dent Res 2011; 22: 499-504.

28. Johnson GH, Drennon DG, Powell GL. Accuracy of elastomeric impressions disinfected by immersion. J Am Dent Assoc 1988; 116: 525-30.

29. Langenwalter EM, Aquilino SA, Turner KA. The dimensional stability of elastomeric impression materials following disinfection. J Prosthet Dent 1990; 63: 270-6.
30. Merchant VA, McNeight MK, Ciborowski CJ, Molinari JA. Preliminary investigation of a method for disinfection of dental impressions. J Prosthet Dent 1984; 52: 877-9.

31. Anıl N, Taşdelen C. Çeşitli sıVı dezenfektanların silikon ölçü maddelerinin boyutsal stabilitesi üzerindeki etkisi. G Ü Diş Hek Fak Derg 1991; 1018.

32. Martin N, Martin MV, Jedynakiewicz NM. The dimensional stability of dental impression materials following immersion in disinfecting solutions. Dent Mater 2007; 23: 760-8.

33. Muzaffar D, Braden M, Parker S, Patel MP. The effect of disinfecting solutions on the dimensional stability of dental alginate impression materials. Dent Mater 2012; 28: 749-55.

34. Carvalhal CI, Mello JA, Sobrinho LC, Correr AB, Sinhoreti MA. Dimensional change of elastomeric materials after immersion in disinfectant solutions for different times. J Contemp Dent Pract 2011; 12: $252-8$.

35. Hamedi Rad F, Ghaffari T, Safavi SH. In vitro evaluation of dimensional stability of alginate impressions after disinfection by spray and immersion methods. J Dent Res Dent Clin Dent Prospects 2010; 4: 130-5

\author{
Yazışma Adresi: \\ Dr. Alper ÖZDOĞAN \\ Atatürk Üniversitesi \\ Diş Hekimliği Fakültesi \\ Protetik Diş Tedavisi AD. \\ ERZURUM \\ TIf 5392018440 \\ e-mil: alprozdgn@gmail.com
}

